Federal Reserve Bank of Minneapolis

Research Department Staff Report 183

October 1994

\title{
Nonuniqueness of Solutions in Applied General Equilibrium Models With Scale Economies and Imperfect Competition*
}

\author{
Jean Mercenier \\ Federal Reserve Bank of Minneapolis \\ and Université de Montréal
}

\begin{abstract}
Applied general equilibrium models with imperfect competition and economies of scale have been extensively used for analyzing international trade and development policy issues. They offer a natural framework for testing the empirical relevance of propositions from the industrial organization and new trade theoretical literature. This paper warns model builders and users that considerable caution is needed in interpreting the results and deriving strong policy conclusions from these models: in this generation of applied general equilibrium models, nonuniqueness of equilibria is not a theoretical curiosum, but a potentially serious problem. Disregarding this may lead to dramatically wrong policy appraisals.
\end{abstract}

*This paper is forthcoming in Economic Theory. The views expressed herein are those of the author and not necessarily those of the Federal Reserve Bank of Minneapolis or the Federal Reserve System. 


\section{Introduction*}

In his path-breaking contribution to the applied general equilibrium literature, Harris (1984) questioned the relevance for policy analysis of models built on the competitive Arrow-Debreu framework. In particular, he suggested that the disappointingly modest evaluations of trade liberalization effects produced by these models are artifacts of the combined assumptions of pricetaking behavior and constant returns to scale in production, features that real economies rarely possess. Building on elements of the new trade theory, he successfully showed this by introducing strategic price-setting behavior and increasing returns to scale at the individual firm level in an otherwise standard applied general equilibrium (GE) model of the Canadian economy. Static applied imperfectly competitive GE models incorporating scale economies have since then been extensively used for analyzing trade liberalization issues, in particular, the Canada-U.S. Free Trade Agreement and the North American Free Trade Agreement (NAFTA) (e.g., Cox and Harris (1985), Wigle (1988), Brown and Stern (1989), Markusen and Wigle (1989), Hunter et al. (1991)) and the European Single Market program (e.g., Gasiorek et al. (1991), Mercenier and Schmitt (1992), Mercenier (1994)), U.S. foreign trade policy issues (e.g., de Melo and Tarr (1992)), and developing countries issues (e.g., Devarajan and Rodrik (1991), de Melo and Roland-Holst (1994)). The role of these models in the recent NAFTA debates demonstrates their potential importance for policy analysis.

For this reason, it is important to call the attention of model builders and users to the fact that considerable caution is needed in interpreting the results and particularly in deriving policy conclusions from models of this vintage: in this area of economics, applied research tends to run ahead of theory because many conceptual issues remain open.

One such problem arises from the possibility that equilibria may not be unique. The whole benchmarking-calibration exercise is on a different logical level in a world with multiple equilibria, and it is not clear what the comparative statics policy exercises really mean in such circumstances. One should presumably then resort to considerations of historical conditions and dynamic stability to pick the "relevant" equilibrium among the set of possible solutions. Obviously, nonuniqueness in static applied GE is a potential serious problem, since modelers can have little confidence in any policy appraisal from their analysis. Yet, nonconvexities in

\footnotetext{
I am particularly indebted to Tim Kehoe both for his comments and for pinpointing a flaw in a previous version of the paper. I also thank for comments, discussions and/or encouragements Irma Adelman, Len Dudley, Robert Gary-Bobo, Rick Harris, Ed Prescott, Jacques Robert, Herb Scarf, T.N. Srinivasan, and an anonymous referee. Needless to say, I remain alone responsible for any error or shortcoming. Financial support from the FCAR of the Government of Québec and from the SSHRC of the Government of Canada and hospitality from the Federal Reserve Bank of Minneapolis are gratefully acknowledged.
} 
production technologies generically imply that the equilibrium will not be unique, as has been known for a long time in the theoretical literature. Despite this, it is remarkable that no case of multiple equilibria has been reported to be encountered in calibrated applied GE models with imperfect competition and economies of scale. Furthermore, an inspection of the literature reveals that applied GE modelers dealing with this vintage of models rarely--if ever--mention the problem. It is as if they feel that the conclusion, inherited from 20 years of practice with competitive GE models, that "nonuniqueness is largely a theoretical curiosum", could safely be extended to models with imperfect competition and increasing returns to scale. It is my objective in this paper to show that this is not the case. ${ }^{1}$

To do this, I use a calibrated, static large-scale applied GE model of trade and production with increasing returns to scale, imperfect competition and product differentiation at the individual firm level. The model is a slightly modified version of the one I used in a previous paper (Mercenier (1994)), and the parameter values are the same (and have therefore not been chosen for the specific needs of this paper). As will be clear from the description in the next section, there is nothing pathological about this model even though it is somewhat more complex than most applied GE models of this vintage in the literature. The trade experiment that will be performed mimics the "Europe 1992" integration program. It consists of forcing a move from an initial equilibrium with segmented price-discriminated national markets to an equilibrium with firms selling at a unique price within the European Economic Community (EEC). Though this experiment, detailed in Section 3, differs from the more usual tariff or tax exercises, it is clearly in the spirit of the new trade theory; see, e.g., Markusen and Venables (1988). In Section 4, I report on two different stable equilibrium allocations that have been numerically identified as the result of the same policy experiment. The paper closes with a brief conclusion.

1 Nonuniqueness of equilibria in competitive economies has been a lurking issue ever since work on applied GE modeling began in the early 1970s following Scarf (1973). Kehoe (1980, 1985a), in particular, provides index theorems along with explicit formulae for calculations of the index of an equilibrium in the presence of production and taxes. However, when translated into economically interpretable restrictions on the parameters of a model, the conditions lose their necessity, so that, to date, whether or not nonuniqueness of equilibria in numerical models of competitive economies is more than a theoretically possible occurrence remains an open question. See Kehoe (1991) for a recent synthesis. It turns out, however, that except for a numerical example of a fictitious though reasonably nonpathological economy produced by Kehoe (1985b), and despite the very large number of applications, no example of multiple equilibria has been reported in the literature. Furthermore, Kehoe and Whalley (1985) report on a systematic exploration of well-known, largescale, static competitive models and conclude to unicity, so that most applied GE modelers regard this potential nonuniqueness problem largely as a theoretical curiosum. This conclusion, although expedient, is to a certain extent further confirmed by the numerical investigation of Kehoe (1985c). Shoven and Whalley (1984, p. 1015) conclude their discussion on the nonuniqueness issue as follows: "The current working hypothesis adopted by most modelers seems to be that uniqueness can be presumed for all of the models discussed here until a clear case of nonuniqueness is found." 
It should be emphasized that the contribution of this paper is to present a numerical example of multiplicity in a model with imperfect competition and economies of scale calibrated on real world data. That multiple equilibria may exist in this type of model has been demonstrated theoretically (e.g., by Venables (1984) and Kemp and Schweinberger (1991)). ${ }^{2}$ Venables (1984) in particular develops a model which has the same basic ingredients as mine. He shows that small perturbations in the parameters of his model may radically change the number and the type of equilibria. He also shows, among other things, that if there are multiple equilibria, there are multiple stable equilibria. My paper demonstrates that the theoretical insight provided by Venables is of practical importance.

\section{The Model}

\section{2.a An overview}

The world economy consists of six countries/regions: Great Britain $(G B)$, the Federal Republic of Germany $(G)$, France $(F r)$, Italy $(I t)$, the rest of the EEC $(R E)$ and the rest of the OECD $(R O W){ }^{3}$ All countries are fully endogenous and have the same structure. Each country has nine sectors of production, of which four are perfectly competitive; see Table 1. In the latter sectors, countries are linked by an Armington system. ${ }^{4}$ The other five industries are noncompetitive, with firms assumed symmetric within national boundaries. They operate with fixed primary factor costs and therefore face increasing returns to scale in production. They have no monopsony power on any market for inputs, primary or intermediate.

Each individual oligopolist produces a different good. The game between noncompetitive firms is Nash in sales. Industry structure is endogenous à la Chamberlain: costless entry and exit ensure zero oligopolistic profits. The instantaneous GE concept adopted is a compromise in terms of informational requirements between the primitive conjectural-Cournot-Nash-Walras equilibrium of Negishi (1961) and the objective-Cournot-Nash-Walras equilibrium introduced by Gabszewicz and Vial (1972). ${ }^{5}$ Namely, noncompetitive firms are endowed with the knowledge of preferences and technologies of their clients, which they use in maximizing profits. They are, however, assumed to neglect the feedback effect of their decisions on their profits via income (the

2 I thank a referee for bringing those papers to my attention.

3 The model is calibrated on a 1982 data base, and region $R E$ actually represents the rest of the EEC-10 partners, and not the 12 present members of the EEC. For details on the data base, calibration procedure and parameter values, see Mercenier (1994).

4 The Armington assumption has been a standard feature of competitive GE trade models; see Shoven and Whalley (1984), Srinivasan and Whalley (1986). Although it is increasingly criticized--see Norman (1990)-it has been adopted here in order to keep the treatment of the competitive side of the model as standard as possible.

5 See also the surveys by Gary-Bobo (1989), Bonanno (1990) and Benassy (1991). 
Ford effect) and input-output multipliers (the Nikaido (1975) effect). ${ }^{6}$ Because of the presence of various forms of nontariff barriers (NTBs) within Europe, national economies are initially assumed segmented, with noncompetitive firms acting as price-discriminating oligopolists; see, e.g., Brander (1981).

Final demand decisions are made in each country by a single representative utilitymaximizing agent. A detailed country- and sector-specific system of price-responsive intermediate demands is specified. All components of demand--final as well as intermediate-recognize differences in products from individual oligopolistic firms, à la Dixit-Stiglitz (1977) and Ethier (1982). Both preferences and technologies, therefore, have increasing returns to varieties, so that product diversity affects not only household utility but also production efficiency in all sectors, competitive and noncompetitive. Both production factors move freely across sectors, with capital being internationally mobile and European labor and labor owners being mobile within the EEC. The model is static: our focus is on induced reallocations of existing resources, and we do not deal with factor accumulation.

\section{2.b A formal presentation}

Sectors of activity are identified by indices $s, t \in S$ with $S=C \cup \bar{C}$ where $C$ and $\bar{C}$ denote, respectively, the subset of competitive and noncompetitive industries. Countries are identified by indices $i, j \in W$ with $W=E E C \cup R O W$, where the first subset represents the European Economic Community and the second the rest of the world. We keep track of the trade flows by identifying the first two indices with, respectively, the country and the industry supplying the good and, when appropriate, the next two with the purchasing country and industry. ${ }^{7}$

\section{$\underline{\text { Households }}$}

Domestic final demand decisions in country $i$ are made by a single representative household. It values competitively produced goods from different countries as imperfect substitutes (the Armington assumption) while it treats goods produced in oligopolistic sectors as firm-specific.

6 This partial equilibrium compromise obviously simplifies the computations. It has also been advocated in the theoretical literature (Hart 1985, p.121) to avoid nonexistence problems highlighted by Roberts and Sonnenschein (1977) and Dierker and Grodal (1986). The implication of such an assumption, however, is that firms are modeled as making their strategic decisions with systematic errors. This is certainly something that a GE modeler should want to avoid. The question is, of course, whether in GE models calibrated on real world data, nonexistence is indeed a serious problem. As a corollary question, are the systematic errors that have been arbitrarily built into the oligopolists' behavior of enough significance to affect the model's prediction when a policy experiment is performed? These are important empirical issues that, to the best of my knowledge, have never been addressed.

7 A subscript $i s j t$ therefore indicates a flow originating in sector $s$ of country $i$ with industry $t$ of country $j$ as recipient. 
This is represented by a two-level utility function. The first level combines consumption goods $\left(c_{. s i}\right)$ assuming constant expenditure shares $\left(\rho_{s i}\right)$. The second level determines the optimal composition of the consumption aggregates in terms of geographical origin if the sector is competitive or in terms of the individual firms' products if the sector is noncompetitive. If we assume that the $n_{j s}$ oligopolistic firms operating in country $j$ 's industry $s$ share the same technology and have equal market shares (the symmetry assumption), ${ }^{8}$ the household's preferences are represented as follows:

$$
U_{i}=\sum_{s \in S} \rho_{s i} \log c_{. s i}, \quad \quad \sum_{s \in S} \rho_{s i}=1
$$

$$
\begin{aligned}
& c_{. s i}=\left\{\sum_{j \in W} \delta_{j s i} c_{j s i}^{\frac{\sigma_{s}-1}{\sigma_{s}}}\right\}^{\frac{\sigma_{s}}{\sigma_{s}-1},} \quad s \in C, \\
& c_{. s i}=\left\{\sum_{j \in W} n_{j s} \delta_{j s i} c_{j s i}^{\frac{\sigma_{s}-1}{\sigma_{s}}}\right\}^{\frac{\sigma_{s}}{\sigma_{s}-1}}, \quad s \in \bar{C},
\end{aligned}
$$

where $\delta_{j s i}$ are share parameters and $\sigma_{s}$ are substitution elasticities. Note that when $s \in C, c_{j s i}$ represents the sales of the whole industry $s$ of country $j$, whereas when $s \in \bar{C}$, it denotes the sales of a single representative firm. For nontraded goods, $\delta_{j s i}=0 \forall j \neq i$.

The household supplies labor and capital services from which it earns its income $Y_{i}=w_{i} \Sigma_{s} L_{i s}+r K_{i}^{s u p}$. Observe from the notation that both primary factors move costlessly across sectors; furthermore, capital is internationally mobile whereas labor and labor owners are assumed to move freely within the EEC. Final demands $c_{j s i}$ of country $i$ result from maximization of (1) subject to the following budget constraint:

$$
\sum_{j \in W}\left(\sum_{s \in C} p_{j s i} c_{j s i}+\sum_{s \in \bar{C}} p_{j s i} n_{j s} c_{j s i}\right) \leq w_{i} \Sigma_{s} L_{i s}+r K_{i}^{s u p}
$$

where $p$ denotes prices.

\section{$\underline{\text { Firms }}$}

Competitive industries. In competitive industries, the representative firm of country $i$ sector $s$ operates with constant returns-to-scale technologies, combining variable capital $\left(K_{i s}^{v}\right)$, labor $\left(L_{i s}^{v}\right)$ and intermediate inputs $\left(x_{j t i s}\right)$ to produce $Q_{i s}$. The treatment of material inputs in the production function is analogous to that of consumption goods in households' preferences:

8 Note that this assumption implies that oligopolists operating in the same country and sector charge identical prices. 
competitively produced goods from different geographical origins enter as imperfect substitutes whereas oligopolistically produced goods are recognized as firm-specific. Formally:

$$
\begin{array}{ll}
\log Q_{i s} & \leq \alpha_{L i s} \log L_{i s}^{v}+\alpha_{K i s} \log K_{i s}^{v}+\sum_{t \in S} \alpha_{t i s} \log x_{. t i s}, \\
x_{. t i s}=\left\{\sum_{j \in W} \beta_{j t i s} x_{j t i s}^{\frac{\sigma_{t}-1}{\sigma_{t}}}\right\}^{\frac{\sigma_{t}}{\sigma_{t}-1},} & t \in C, \\
x_{. t i s}=\left\{\sum_{j \in W} n_{j t} \beta_{j t i s} x_{j t i s} \frac{\sigma_{t}-1}{\sigma_{t}}\right\}^{\frac{\sigma_{t}}{\sigma_{t}-1},} & t \in \bar{C},
\end{array}
$$

where $\alpha$ s and $\beta$ s are share parameters with

$$
\alpha_{L i s}+\alpha_{K i s}+\sum_{t \in S} \alpha_{t i s}=1
$$

and $\beta_{j t i s}=0 \forall j \neq i$ if $t$ is nontraded. ${ }^{9}$ Input demands result from minimizing variable costs $v_{i s}$ for given output levels $Q_{i s}$ :

$$
v_{i s} Q_{i s}=\sum_{j \in W}\left(\sum_{t \in C} p_{j t i} x_{j t i s}+\sum_{t \in \bar{C}} p_{j t i} n_{j t} x_{j t i s}\right)+w_{i} L_{i s}^{v}+r K_{i s}^{v}
$$

subject to (3), which implies marginal cost pricing: $p_{i s j}=v_{i s}$.

Noncompetitive industries. Noncompetitive firms have increasing returns to scale in production: in addition to variable costs associated with technological constraints similar to (3), they face fixed primary factor costs. This introduces a wedge between average $\left(V_{i s}\right)$ and marginal $\left(v_{i s}\right)$ costs:

$$
V_{i s}=v_{i s}+\frac{\left[w_{i} L_{i s}^{F}+r K_{i s}^{F}\right]}{Q_{i s}}, \quad s \in \bar{C}
$$

where $Q_{i s}, L_{i s}^{F}, K_{i s}^{F}$ denote, respectively, the individual firm's output, fixed labor and fixed capital.

With initial market segmentation, the noncompetitive firm exploits the monopoly power it has on each individual country market. To establish this, the firm is endowed with the knowledge of preferences (1) and technologies (3) of its clients. It then performs a partial equilibrium profit

9 Observe that although goods enter preferences (1) and technologies (3) with the same degree of differentiation (the $\sigma$ s are assumed identical by lack of evidence otherwise), price responsiveness will not be the same because the share parameters are different: the $\beta$ s are sector-specific. 
maximization calculation assuming that in each country, each individual client's current-price expenditure on the whole industry is unaffected by its own strategic action $z_{i s j}$, so that

(6) $\frac{\partial \rho_{s j} Y_{j}}{\partial z_{i s j}}=0, j=1, \ldots, W, \quad$ and $\quad \frac{\partial \alpha_{s j t} v_{j t} Q_{j t}}{\partial z_{i s j}}=0, j=1, \ldots, W, \quad t=1, \ldots, S$.

We make the Cournot assumption of noncooperative behavior with sales to each individual market as the strategic variables $z_{i s j}$. Profit maximization then yields that

(7) $\frac{p_{i s j}-v_{i s}}{p_{i s j}}=\frac{\partial \log p_{i s j}}{\partial \log z_{i s j}}, \quad s \in \bar{C}$,

with

(8) $Q_{i s}=\sum_{j \in W} z_{i s j}$.

The computation of the elasticities on the right side of (7) requires inverting log-linearized aggregate demand systems. This is a very complex calculation; see the Appendix for details.

Costless entry/exit ensures that oligopolists make zero profits:

$$
V_{i s} Q_{i s}-\sum_{j \in W} p_{i s j} z_{i s j}=0, \quad s \in \bar{C}
$$

$\underline{\text { General equilibrium }}$

A general equilibrium is an allocation, supported by a vector of prices $\left(p_{i s j}, w_{i}, r\right)$, $s \in S, i, j \in W$, such that

- Households maximize (1) subject to (2);

- Firms minimize (4) subject to (3);

- Oligopolistic firms set prices according to (7) and satisfy the resulting demand so that

$$
z_{i s j}=c_{i s j}+\sum_{t \in S} x_{i s j t}, \quad s \in \bar{C}, \quad i, j \in W
$$

and (8) holds; 
- Industry concentration--as summarized by the real variable $n_{i s^{-}}$is such that noncompetitive firms earn no pure profits; i.e., conditions (5) and (9) are satisfied.10 For the pricing equation (7) to make sense requires that the equilibrium number of firms $n_{i s}$ be greater than one:

$n_{i s} \geq 1, \quad s \in \bar{C}$

- Supply equals demand in each competitive market:

$$
\begin{aligned}
& Q_{i s}=\sum_{j \in W}\left[c_{i s j}+\sum_{t \in S} x_{i s j t}\right], \quad s \in C, i \in W \\
& \sum_{i \in W} K_{i}^{\text {sup }}=\sum_{i \in W}\left(\sum_{s \in C} K_{i s}^{v}+\sum_{s \in \bar{C}} n_{i s}\left[K_{i s}^{v}+K_{i s}^{F}\right]\right), \quad \text { with } K_{i}^{\text {sup fixed; }}
\end{aligned}
$$

$$
L_{i}^{\text {sup }}=\sum_{s \in S} L_{i s}=\sum_{s \in C} L_{i s}^{v}+\sum_{s \in \bar{C}} n_{i s}\left[L_{i s}^{v}+L_{i s}^{F}\right], \quad i \in R O W
$$

$$
\frac{w_{i}}{p_{\mathrm{c} i}}=\frac{w_{j}}{p_{\mathrm{c} j}}, \quad i, j \in E E C
$$

$$
L_{E E C}^{\text {sup }}=\sum_{i \in E E C} \sum_{s \in S} L_{i s}=\sum_{i \in E E C}\left(\sum_{s \in C} L_{i s}^{v}+\sum_{s \in \bar{C}} n_{i s}\left[L_{i s}^{v}+L_{i s}^{F}\right]\right)
$$

where $p_{\mathrm{c}}$ refers to the consumption price index and $L^{\text {sup }}$ to exogenously given labor stocks.

The ROW wage rate is chosen as the numéraire. ${ }^{11}$ Calibration of the model to a base-year data set is made difficult because of equation (7). It requires the joint determination of the

10 The treatment of $n_{i s}$ as a real rather than an integer variable is widespread both in the theoretical trade literature and in the applied GE literature (for the latter, Mercenier and Schmitt (1992) is a notable exception). The reason for this is that it drastically simplifies both the analytics and the computations. (One would otherwise have to resort to mixed-integer programming techniques which are presently unable to handle large-scale nonlinear problems.) Though quite innocuous for many sectors where $n_{i s}$ is large, such an assumption may be thought to make little sense for highly concentrated industries. One has to consider, however, that the hypothesis is made jointly with that of symmetry, so that, in any case, firms are abstract objects. One should therefore regard $n_{i s}$ as an index of product variety rather than, strictly speaking, as a number of real world firms.

11 It is well known that price normalization matters in the objective-Cournot-Nash-Walras GE model; see Gabszewicz and Vial (1972). This raises important questions concerning the theoretical consistency of the Cournot-Walras construction. Ginsburgh (1994) has recently called attention to the issue by producing a numerical example in which manipulating the numéraire may be more welfare-improving than removing market imperfections such as consumer taxes. If we disregard theoretical consistency issues, a practical way out of this numéraire problem is to choose a normalization rule that involves only competitive prices. In addition, we consider only zero-profit equilibria which are, as shown by Kletzer and Srinivasan (1994), immune to changes in the normalization rule. 
markups and scale elasticities consistent with observed base-year expenditures and optimal price discrimination; see Mercenier (1994) for details.

\section{The Trade Experiment: Completing the European Single Market}

Following Smith and Venables' (1988) formalization of the completion of a single market in Europe, the numerical experiment consists of forcing individual firms to switch from their initial segmented-market pricing strategy to an integrated-market pricing strategy determined from their average EEC-wide monopoly power. ${ }^{12}$

The rationale underlying this experiment is the following. Although tariffs within Europe are negligible, significant NTBs subsist, taking various more-or-less pernicious forms such as norms, government procurement policies and security regulations. ${ }^{13}$ These barriers confer to firms the power to price-discriminate among national markets. The objective of the "Europe 1992" program is to restore cross-border arbitraging by suppressing all forms of NTBs. Firms would then be forced to charge a unique price within the EEC. Quantifying these effects is difficult because NTBs are essentially unobservable. ${ }^{14}$ The modeling strategy adopted treats these NTBs as latent variables underlying market segmentation within the community in the pre"1992" equilibrium. We infer from the data set the price system consistent with optimal price discrimination by oligopolistic firms and interpret these as resulting from the implicit structure of NTBs. The policy experiment then consists of forcing individual firms to adopt single-pricing within Europe, determined from their average EEC-wide monopoly power, and interpreting this behavioral change as the optimal strategic reaction to the elimination of the implicit NTBs.

Formally, we rewrite the pricing equation (7) as

$$
\frac{p_{i s j}-v_{i s}}{p_{i s j}}=\lambda \frac{\partial \log p_{i s j}}{\partial \log z_{i s j}}+(1-\lambda) \frac{\partial \log p_{i s E E C}}{\partial \log z_{i s E E C}}, \quad s \in \bar{C},
$$

where $p_{i s E E C}$ and $z_{i s E E C}$ denote, respectively, prices and sales to a single Europe-wide market. The model is calibrated with $\lambda=1$; market integration is implemented by setting $\lambda=0$. See the Appendix for details on the numerical evaluation of $\partial \log p_{i s E E C} / \partial \log z_{i s E E C}$.

\section{Results}

12 The "Europe 1992" integration program aims at the abolition of all barriers to movements of goods and production factors within the EEC. It includes explicit efforts to ease labor mobility, a feature that we have taken into account by our modeling of the factor markets.

13 See, e.g., CEC (1988) for an extensive identification of these barriers.

14 It is, of course, well known that there is no such thing as a tariff-equivalence to NTBs in a noncompetitive environment. 
Table 2 documents two equilibrium allocations predicted by the model for the same policy experiment. ${ }^{15}$ These spectacular results speak clearly for themselves, and I make only a few comments.

(1) Both equilibria have been conclusively tested for local stability in the sense that when started from initial values generated by $\pm 1 \%$ random perturbations of equilibrium allocations and prices, the (Newton-type) algorithm converges back to the same equilibrium.

(2) The two equilibria have been obtained by forcing the algorithm on different search paths by randomly choosing the competitive market-equilibrium condition that is being dropped thanks to Walras' law. Needless to say, that the model satisfies Walras's law is verified by checking that at the solution allocations and prices, all markets clear and all agents are on their budget constraints.

(3) It should be emphasized that it would be heroic to infer that the model has only two equilibria from the fact that I have been unable to produce more than two. As is made clear above, one has to resort to ad hoc trial and error-type explorations, most trial shots ending with the algorithm blowing out of numerical control. It is likely that, were it possible to exert a fuller control on the algorithm so that one could monitor the numerical search more widely in the feasible space, additional equilibria would be found. More generally, I want to suggest that nonuniqueness may well be the general rule rather than the exception in this generation of GE models and that if cases of multiple equilibria have not been encountered before, it has more to do with the limitations of our numerical abilities and techniques than with the properties of the models.

(4) An extensive investigation of the case with fixed industry structure (namely, the number of firms is held fixed and oligopolistic profits are not necessarily zero anymore) has failed to produce more than one equilibrium. ${ }^{16}$ This suggests that the Chamberlinian assumption of costless entry/exit could be a potential source of multiplicity (which can hardly be surprising given that preferences and production technologies exhibit increasing returns to the number of

15 In a previous version of this paper, I reported four different solution allocations. Tim Kehoe brought to my attention that two of these were in fact infeasible, since some computed $n_{\text {is }}$ were smaller than unity. Condition (11) has been added to the model, and the results reported here do satisfy the constraint.

All computations have been performed using GAMS/MINOS (Brooke et al. (1988)), which is the most popular software among GE modelers. GAMS/MINOS uses a projected Lagrangian algorithm; see Murtagh and Saunders (1982).

The database, the code and the detailed equilibrium values for allocations, prices and parameters are available from the author upon request (before one year past the date of publication of the paper) preferably by E-mail (mercenie@plgcn.umontreal.ca) or by mail (CRDE, Universite de Montreal, CP 6128, Suc. A, Montreal, $\mathrm{H} 3 \mathrm{C} 3 \mathrm{~J} 7$, Canada) if a disk is supplied with the request.

16 Needless to say, budget constraints (2) have then been appropriately amended to include profits on the income side. 
varieties). This is troublesome if one bears in mind that this mechanism is a cornerstone of the rationalization of production effects forcefully stressed by Harris (1984) in his evaluations of the positive welfare gains for Canada of the Canada-U.S. Free Trade Agreement. A proviso, however: the factor mobility assumption may not be innocuous either; it could well be a necessary condition (certainly not a sufficient one, according to my numerical tests) for making the multiplicity apparent (see Helpman and Krugman (1985, section 10.3)). The theoretical insight provided by Venables (1984) suggests, however, that the problem is potentially serious even with fixed national factor endowments.

(5) The two identified equilibria cannot be Pareto-ranked.

\section{Conclusion}

The existence of multiple equilibria in models of international trade with imperfect competition is not novel. Yet, the problem seems to have been largely ignored by applied GE modelers, or at least its importance has been underestimated. This paper has shown that nonuniqueness is a potentially serious problem in models that are currently being used for policy analysis. My contribution has been to present a numerical example of multiplicity in a rather standard (though admittedly more sophisticated than usual) large-scale applied GE model calibrated on real world data.

In the specific model presented here, the source of the nonuniqueness result seems to be in the assumption of costless entry and exit of firms. This is troubling given that this Chamberlinian mechanism plays an important role in many applied GE models of this vintage. It is in particular a cornerstone of the rationalization of production effects forcefully stressed by Harris (1984).

What is the appropriate methodological response to this nonuniqueness problem? There is no easy answer to this question because many conceptual issues remain unaddressed. A fullfledged dynamic theory of oligopolistic markets would certainly help to solve the nonuniqueness problem. Since such a theory is not yet available despite recent progress (e.g., Maskin and Tirole (1987, 1988a,b)), considerable caution should be used in deriving strong policy conclusions from these models. 


\section{References}

Benassy, J.P., 1991, "Monopolistic Competition", in: Handbook of Mathematical Economics, Vol. IV, W. Hildenbrand and H. Sonnenschein (eds.), pp. 1997-2045. Amsterdam: North-Holland.

Bonanno, G., 1990, "General Equilibrium Theory with Imperfect Competition", Journal of Economic Surveys 4, 297-328.

Brander, J., 1981, "Intra-Industry Trade in Identical Commodities", Journal of International Economics 11, 1-14.

Brooke, A., D. Kendrick and A. Meeraus, 1988, GAMS: A User's Guide. San Francisco: Scientific Press.

Brown, D.K. and R.M. Stern, 1989, "U.S.-Canada Bilateral Tariff Elimination: The Role of Product Differentiation and Market Structure", in: Trade Pólicies for International Competitiveness, R.C. Feenstra (ed.), pp. 217-245. Chicago: University of Chicago Press.

Commission of the European Communities (CEC), 1988, "The Economics of 1992", The European Economy 35.

Cox, D. and R. Harris, 1985, "Trade Liberalization and Industrial Organization: Some Estimates for Canada", Journal of Political Economy 93, 115-145.

Devarajan, S. and D. Rodrik, 1991, "Pro-Competitive Effects of Trade Reform: Results from a CGE Model of Cameroon", European Economic Review 35, 1157-1184.

Dierker, H. and B. Grodal, 1986, "Nonexistence of Cournot-Walras Equilibrium in a General Equilibrium Model with Two Oligopolists", in: Contributions to Mathematical Economics in Honor of Gerard Debreu, W. Hildenbrand and A. Mas-Colell (eds), pp. 167-185. Amsterdam: North-Holland.

Dixit, A.K. and J.E. Stiglitz, 1977,"Monopolistic Competition and Optimum Product Diversity", American Economic Review 67, 297-308.

Ethier, W.J., 1982, "National and International Returns to Scale in the Modern Theory of International Trade", American Economic Review 72, 389-405.

Gabszewicz, J.J. and J.P. Vial, 1972, "Oligopoly 'à la Cournot' in a General Equilibrium Analysis", Journal of Economic Theory 4, 381-400.

Gary-Bobo, R.J., 1989, Équilibre Général et Concurrence Imparfaite, monographie d'économétrie. Paris: éditions du CNRS.

Gasiorek, M., A. Smith and A.J. Venables, 1991, "Completing the Internal Market in the European Community: Factor Demands and Comparative Advantage", in: 1992: Trade and Industry, A.J. Venables and L.A. Winters (eds.), pp. 9-51. Cambridge: Cambridge University Press. 
Ginsburgh, V., 1994, "In the Cournot-Walras General Equilibrium Model, There May Be 'More to Gain' by Changing the Numeraire, than by Eliminating Imperfections: A Two-Good Economy Example", in: Applied General Equilibrium Analysis and Economic Development, J. Mercenier and T.N. Srinivasan (eds.), pp. 217-224. Ann Harbor: University of Michigan Press.

Harris, R., 1984, "Applied General Equilibrium Analysis of Small Open Economies with Scale Economies and Imperfect Competition", American Economic Review 74, 1016-1032.

Hart, O.D., 1985, "Imperfect Competition in General Equilibrium: An Overview of Recent Work", in: Frontiers of Economics, K.J. Arrow and S. Honkapohja (eds.), pp. 100149. Oxford: Blackwell.

Helpman, E. and P.R. Krugman, 1985, Market Structure and Foreign Trade. Cambridge: MIT Press.

Hunter, L., J.R. Markusen and T.F. Rutherford, 1991, "Trade Liberalization in a MultinationalDominated Industry: A Theoretical and Applied General-Equilibrium Analysis", NBER Working Paper 3679.

Kehoe, T.J., 1980, "An Index Theorem for General Equilibrium Models with Production", Econometrica 48, 1211-1232.

Kehoe, T.J., 1985a, "The Comparative Statics Properties of Tax Models", Canadian Journal of Economics 18, 314-334.

Kehoe, T.J., 1985b, "Multiplicity of Equilibria and Comparative Statics", Quarterly Journal of Economics 100, 119-147.

Kehoe, T.J., 1985c, "A Numerical Investigation of Multiplicity of Equilibria", Mathematical Programming Study 23, 240-258.

Kehoe, T.J., 1991, "Computation and Multiplicity of Equilibria", in: Handbook of Mathematical Economics, Vol. IV, W. Hildenbrand and H. Sonnenschein (eds.), pp. 2049-2143. Amsterdam: North-Holland.

Kehoe, T.J. and J. Whalley, 1985, "Uniqueness of Equilibrium in Large-Scale Numerical General Equilibrium Models", Journal of Public Economics 28, 247-254.

Kemp, M.C. and A.G. Schweinberger, 1991, "Variable Returns to Scale, Non-Uniqueness of Equilibrium and the Gains from International Trade", Review of Economic Studies 58, 807-816.

Kletzer, K. and T.N. Srinivasan, 1994, "Price Normalization and Equilibria in General Equilibrium Models of International Trade Under Imperfect Competition", Discussion Paper 710, Economic Growth Center, Yale University (April).

Markusen, J.R. and A.J. Venables, 1988, "Trade Policy with Increasing Returns and Imperfect Competition: Contradictory Results From Competing Assumptions", Journal of International Economics 24, 299-316.

Markusen, J.R. and R.M. Wigle, 1989, "Nash Equilibrium Tariffs for the United States and Canada: The Roles of Country Size, Scale Economies and Capital Mobility", Journal of Political Economy 97 (2), 368-386. 
Maskin, E. and J. Tirole, 1987, "A Theory of Dynamic Oligopoly, III: Cournot Competition", European Economic Review 31, 947-968.

Maskin, E. and J. Tirole, 1988a, "A Theory of Dynamic Oligopoly, I: Overview and Quantity Competition with Large Fixed Costs", Econometrica 56, 549-569.

Maskin, E. and J. Tirole, 1988b, "A Theory of Dynamic Oligopoly, II: Price Competition, Kinked Demand Curves, and Edgeworth Cycles", Econometrica 56, 571-599.

Melo, J. de, and D. Roland-Holst, 1994, "Tariffs and Export Subsidies When Domestic Markets are Oligopolistic", in: Applied General Equilibrium Analysis and Economic Development, J. Mercenier and T.N. Srinivasan (eds.), pp. 191-208. Ann Harbor: University of Michigan Press.

Melo, J. de, and D. Tarr, 1992, A General Equilibrium Analysis of U.S. Foreign Trade Policy. Cambridge: MIT Press.

Mercenier, J., 1994, "Can '1992' Reduce Unemployment in Europe? On Welfare and Employment Effects of Europe's Move to a Single Market", Journal of Policy Modeling, forthcoming.

Mercenier, J. and N. Schmitt, 1992, "On Sunk Costs and Trade Liberalization in Applied General Equilibrium (with implications for 'Europe 1992')", Discussion Paper 3992, C.R.D.E., Université de Montreal.

Murtagh, B.A. and M.A. Saunders, 1982, "A Projected Lagrangian Algorithm and Its Implementation for Sparse Nonlinear Constraints", Mathematical Programming Study $16,84-117$.

Negishi, T., 1961, "Monopolistic Competition and General Equilibrium", Review of Economic Studies 28, 196-201.

Nikaido, H., 1975, Monopolistic Competition and Effective Demand. Princeton, N.J.: Princeton University Press.

Norman, V.D., 1990, "Assessing Trade and Welfare Effects of Trade Liberalization: A Comparison of Alternative Approaches to CGE Modeling with Imperfect Competition", European Economic Review 34, 725-745.

Roberts, J. and H. Sonnenschein, 1977, "On the Foundations of the Theory of Monopolistic Competition", Econometrica 45, 101-113.

Scarf, H.E. (with T. Hansen), 1973, The Computation of Economic Equilibria . New Haven, Conn.: Yale University Press.

Shoven, J.B. and J. Whalley, 1984, "Applied General-Equilibrium Models of Taxation and International Trade: An Introduction and Survey", Journal of Economic Literature 22, 1007-1051.

Smith, A. and A.J. Venables, 1988, "Completing the Internal Market in the European Community: Some Industry Simulations", European Economic Review 32, 1501-1525.

Srinivasan, T.N. and J. Whalley (ed), 1986, General Equilibrium Trade Policy Modeling. Cambridge: MIT Press. 
Venables, A.J., 1984, "Multiple Equilibria in the Theory of International Trade with Monopolistically Competitive Commodities", Journal of International Economics 16, 103-121.

Wigle, R.M., 1988, "General Equilibrium Evaluation of Canada-US. Trade Liberalization in a Global Context", Canadian Journal of Economics 21, 539-564. 


\section{Appendix: The computation of oligopolistic markups}

\section{a) The segmented market case}

The difficulty in this exercise is that one has to keep track of individual firms' variables. Let us define $\mathbf{P}_{j}$ as the vector of prices on market $j$ :

$$
\mathbf{P}_{j}^{\prime}=\left[p_{1 j}^{1}, \ldots, p_{1 j}^{n_{1}}, \ldots, p_{i j}^{1}, \ldots, p_{i j}^{f}, \ldots, p_{i j}^{n_{i}}, \ldots, p_{W j}^{1}, \ldots, p_{W j}^{n_{W}}\right]
$$

where $p_{i j}^{f}$ is the price charged by firm $f$ of country $i$. (For notational convenience, we neglect the subscript s.) Define in a similar way $\mathbf{Z}_{j}, \mathbf{C}_{j}, \mathbf{X}_{j t}$ as the vectors of sales $\left(z_{i j}^{f}\right)$, consumption $\left(c_{i j}^{f}\right)$ and input demands by sector $t\left(x_{i j t}^{f}\right)$. On market $j$, firms face a demand system that, according to assumptions (6), is of the following form:

(A1) $\mathbf{Z}_{j}=\mathbf{C}_{j}\left(\mathbf{P}_{j}\left(\mathbf{Z}_{j}\right)\right)+\sum_{t} \mathbf{X}_{j t}\left(\mathbf{P}_{j}\left(\mathbf{Z}_{j}\right)\right)$

Total differentiation yields that

$$
\mathbf{d Z}_{j}=\left[\frac{\partial \mathbf{C}_{j}}{\partial \mathbf{P}_{j}}+\sum_{t} \frac{\partial \mathbf{X}_{j t}}{\partial \mathbf{P}_{j}}\right] \cdot \frac{\partial \mathbf{P}_{j}}{\partial \mathbf{Z}_{j}} \mathbf{d} \mathbf{Z}_{j}
$$

where $\partial \mathbf{C}_{j} / \partial \mathbf{P}_{j}, \partial \mathbf{X}_{j t} / \partial \mathbf{P}_{j}, \partial \mathbf{P}_{j} / \partial \mathbf{Z}_{j}$ are matrices of partial derivatives. Define $\widehat{\mathbf{P}}_{j}$ as the diagonal matrix with the $p_{i j}^{f}$ as diagonal elements and $\widehat{\mathbf{C}}_{j}, \widehat{\mathbf{X}}_{j t}, \widehat{\mathbf{Z}}_{j}$ in a similar way. It is then trivial to transform the previous system to exhibit elasticities:

$$
\begin{aligned}
\mathbf{d} \mathbf{Z}_{j} & =\left[\frac{\partial \mathbf{C}_{j}}{\partial \mathbf{P}_{j}} \widehat{\mathbf{P}}_{j} \widehat{\mathbf{C}}_{j}^{-1} \widehat{\mathbf{C}}_{j} \widehat{\mathbf{Z}}_{j}^{-1}+\sum_{t} \frac{\partial \mathbf{X}_{j t}}{\partial \mathbf{P}_{j}} \widehat{\mathbf{P}}_{j} \widehat{\mathbf{X}}_{j t}^{-1} \widehat{\mathbf{X}}_{j t} \widehat{\mathbf{Z}}_{j}^{-1}\right] \cdot \widehat{\mathbf{P}}_{j}^{-1} \widehat{\mathbf{Z}}_{j} \frac{\partial \mathbf{P}_{j}}{\partial \mathbf{Z}_{j}} \mathbf{d} \mathbf{Z}_{j} \\
& =\left[\boldsymbol{\varepsilon}\left(\mathbf{C}_{j}, \mathbf{P}_{j}\right) \widehat{\mathbf{C}}_{j} \widehat{\mathbf{Z}}_{j}^{-1}+\sum_{t} \boldsymbol{\varepsilon}\left(\mathbf{X}_{j t}, \mathbf{P}_{j}\right) \widehat{\mathbf{X}}_{j t} \widehat{\mathbf{Z}}_{j}^{-1}\right] \cdot \boldsymbol{\varepsilon}\left(\mathbf{P}_{j}, \mathbf{Z}_{j}\right) \mathbf{d} \mathbf{Z}_{j}
\end{aligned}
$$

Noncooperative behavior implies that firm $f$ solves this system with $\mathbf{d} z_{i j}^{f}=1$ and all other elements of $\mathbf{d} \mathbf{Z}_{j}$ set to zero. This yields the value of the right-side term of (7) for firm $f$. Conceptually, the computation of an equilibrium requires solving one such system for each firm to all destination markets. The cost of such a calculation would be prohibitive without the assumption of symmetry between domestic firms.

To work a tractable formula, we introduce the following notation for cross-elasticities: 


$$
\left.\begin{array}{rl}
\varepsilon_{i j}^{k} & =\frac{\partial \log \left(c_{i j}^{f}+\sum_{t} x_{i j t}^{f}\right)}{\partial \log p_{k j}^{g}} \\
\psi_{i j}^{k} & =\frac{\partial \log p_{i j}^{f}}{\partial \log z_{k j}^{g}}
\end{array}\right\} f \in i, g \in k, f \neq g
$$

and identify the corresponding own-elasticities by a tilde $(\sim)$ :

$$
\left.\begin{array}{l}
\tilde{\varepsilon}_{i j}^{i}=\frac{\partial \log \left(c_{i j}^{f}+\sum_{t} x_{i j t}^{f}\right)}{\partial \log p_{i j}^{f}} \\
\tilde{\psi}_{i j}^{i}=\frac{\partial \log p_{i j}^{f}}{\partial \log z_{i j}^{f}}
\end{array}\right\} f \in i .
$$

Observe that $\widetilde{\psi}_{i j}^{i}$ is the variable on the right side of the pricing equation (7). There is a simple relationship between own- and cross-elasticities:

$$
\begin{gathered}
\tilde{\varepsilon}_{i j}^{i}=\varepsilon_{i j}^{i}-\sigma \\
\widetilde{\psi}_{i j}^{i}=\psi_{i j}^{i}-\frac{1}{\sigma}
\end{gathered}
$$

which reduces by one the dimension of the system (A2). From this and the symmetry assumption, it can then be shown by standard though tedious algebra that the system (A2) takes the following form:

(A4) $0=\sum_{k \in W}\left(n_{k}-\delta_{k i}\right) \varepsilon_{h j}^{k} \psi_{k j}^{i}-\sigma \psi_{h j}^{i}+\varepsilon_{h j}^{i}\left(\psi_{i j}^{i}-\frac{1}{\sigma}\right), \quad h=1, \ldots, W$, where $\delta_{k i}= \begin{cases}1 & \text { if } k=i \\ 0 & \text { if } k \neq i\end{cases}$

An analytical expression for the cross-price elasticities $\varepsilon_{h j}^{k}$ is easily derived from preferences (1), technologies (3) and assumptions (6):

(A5) $\varepsilon_{h j}^{k}=[\sigma-1]\left\{\frac{c_{h j}}{\left[c_{h j}+\sum_{t} x_{h j t}\right]} \frac{p_{k j} c_{k j}}{\rho_{j} Y_{j}}+\sum_{t}\left[\frac{x_{h j t}}{\left[c_{h j}+\sum_{t} x_{h j t}\right]} \frac{p_{k j} x_{k j t}}{\alpha_{j t} v_{j t} Q_{j t}}\right]\right.$.

Solving (A4) and (A5) for $h=1, \ldots, W$, and making use of (A3), one obtains the value of the right side of (7). This calculation has to be performed $\forall i, j \in W$, in each noncompetitive sector $s \in \bar{C}$. 


\section{b) The integrated market case}

The only difference between the segmented and integrated market cases is that in the latter one has to deal with the EEC-aggregate demand system rather than with demands from individual countries. System (A4) remains essentially unchanged (market $j$ now representing the aggregate EEC market), but the price elasticities are now weighted averages of those of individual countries:

(A6) $\varepsilon_{h E E C}^{k}=\frac{\sum_{j \in E E C} \varepsilon_{h j}^{k}\left[c_{h j}+\sum_{t} x_{h j t}\right]}{\sum_{j \in E E C}\left[c_{h j}+\sum_{t} x_{h j t}\right]}$. 


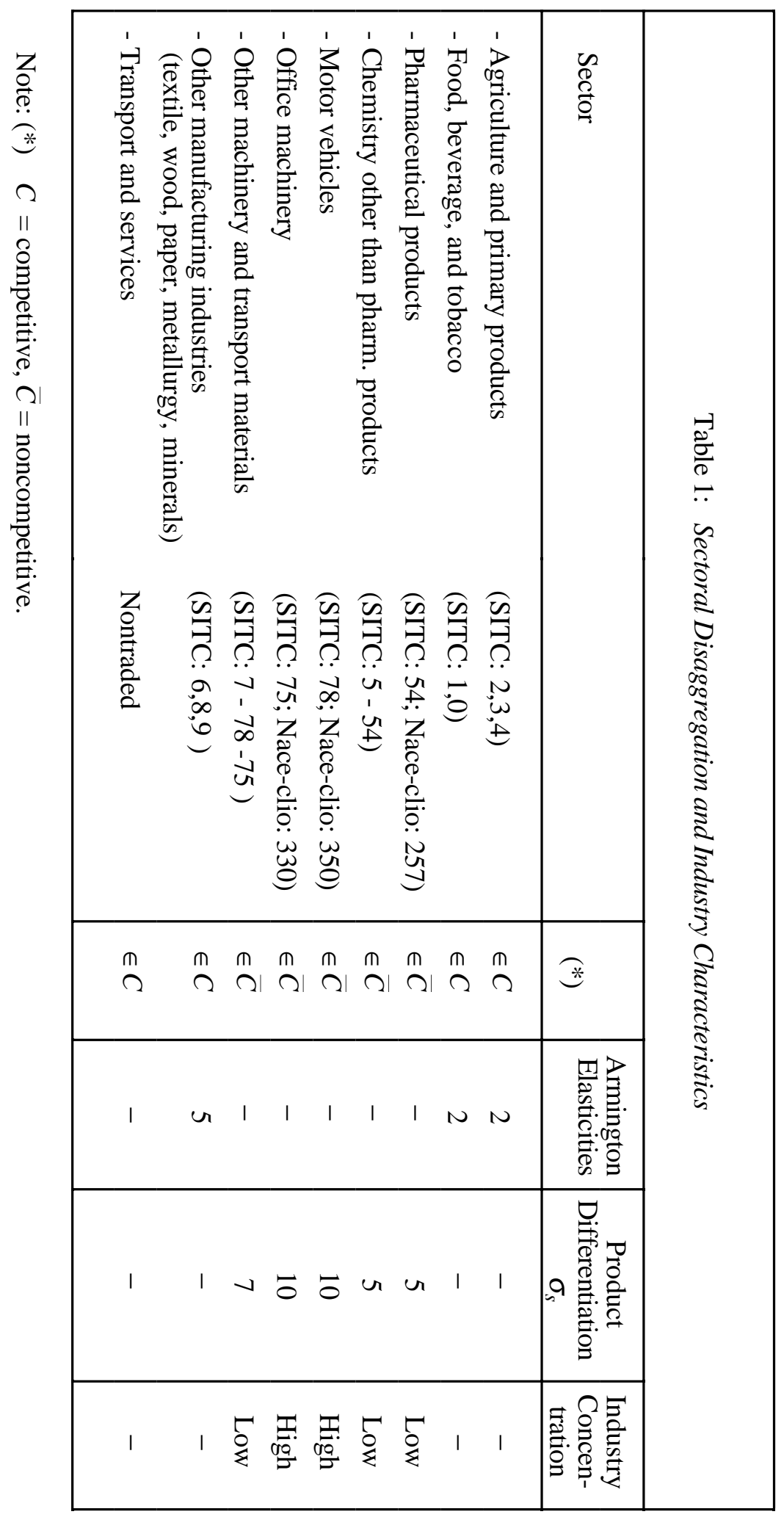


Table 2:

Numerical Results of the 'Europe 1992' Experiment

(\% deviations $w$. r. to calibrated segmented market equilibrium)

\begin{tabular}{|c|c|c|c|c|c|c|}
\hline \multicolumn{7}{|c|}{ Equilibrium \# 1} \\
\hline & $G B$ & $G$ & $\mathrm{Fr}$ & It & $R E$ & $R O W$ \\
\hline Real income & -12.74 & 6.33 & -6.08 & 1.61 & 13.71 & -0.03 \\
\hline Wage rate & 4.83 & -1.13 & 2.23 & 0.03 & -0.91 & 0.00 \\
\hline Rental rate of capital & 0.48 & 0.48 & 0.48 & 0.48 & 0.48 & 0.48 \\
\hline Cost of living index & 4.26 & -1.66 & 1.68 & -0.51 & -1.45 & 0.24 \\
\hline Employment & -21.34 & 8.84 & -10.48 & 1.61 & 26.17 & 0.00 \\
\hline Output & & & & & & \\
\hline Pharmaceutics & -36.13 & 28.09 & -16.21 & 1.93 & 24.41 & -0.43 \\
\hline Chemicals (nonpharm.) & -29.78 & 20.60 & -15.06 & 1.39 & 19.95 & -0.51 \\
\hline Motor vehicles & -18.65 & 2.45 & -16.19 & 15.73 & 121.82 & -1.54 \\
\hline Office machinery & -66.31 & 13.38 & -42.35 & 4.48 & 309.64 & -2.99 \\
\hline Other mach. \& transp. & -34.78 & 16.62 & -22.63 & 2.81 & 114.76 & -0.77 \\
\hline Number of firms & & & & & & \\
\hline Pharmaceutics & -34.90 & 22.71 & -15.97 & 0.03 & 21.06 & -0.40 \\
\hline Chemicals (nonpharm.) & -27.66 & 16.76 & -14.40 & 0.56 & 18.78 & -0.47 \\
\hline Motor vehicles & -31.19 & -7.58 & -13.98 & 7.54 & 78.18 & -0.75 \\
\hline Office machinery & -67.99 & -0.30 & -46.23 & -19.11 & 266.29 & -2.87 \\
\hline Other mach. \& transp. & -33.87 & 14.30 & -23.33 & 0.95 & 106.95 & -0.75 \\
\hline
\end{tabular}

Equilibrium \# 2

\begin{tabular}{|l|r|r|r|r|r|r|}
\cline { 2 - 7 } & \multicolumn{1}{|c|}{$G B$} & \multicolumn{1}{c|}{$G$} & \multicolumn{1}{c|}{$F r$} & \multicolumn{1}{c|}{ I } & \multicolumn{1}{c|}{ RE } & \multicolumn{1}{c}{ ROW } \\
\hline Real income & 2.79 & 6.13 & -5.73 & 1.21 & -2.89 & -0.02 \\
Wage rate & 0.37 & -0.52 & 2.72 & 0.61 & 1.80 & 0.00 \\
Rental rate of capital & 0.26 & 0.26 & 0.26 & 0.26 & 0.26 & 0.26 \\
Cost of living index & -0.44 & -1.32 & 1.89 & -0.19 & 0.98 & 0.14 \\
Employment & 3.82 & 8.62 & -9.77 & 1.06 & -6.09 & 0.00 \\
Output & & & & & & \\
Pharmaceutics & 5.80 & 22.13 & -16.61 & 0.59 & -6.42 & -0.60 \\
Chemicals (nonpharm.) & 5.75 & 18.14 & -14.12 & 1.17 & -6.65 & -0.47 \\
Motor vehicles & 28.14 & 5.37 & -14.97 & 14.40 & -2.63 & -1.16 \\
Office machinery & 13.52 & 23.02 & -37.17 & 7.93 & -52.14 & -0.02 \\
Other mach. \& transp. & 6.94 & 17.64 & -18.86 & 2.70 & -23.05 & -0.48 \\
Number of firms & & & & & & \\
Pharmaceutics & 2.31 & 17.45 & -16.44 & -1.08 & -8.26 & -0.58 \\
Chemicals (nonpharm.) & 4.49 & 14.72 & -13.50 & 0.48 & -7.14 & -0.44 \\
Motor vehicles & 6.57 & -3.39 & -10.31 & 9.15 & -5.80 & -0.53 \\
Office machinery & 1.61 & 8.45 & -41.59 & -15.43 & -54.92 & -0.04 \\
Other mach. \& transp. & 5.34 & 15.36 & -19.60 & 0.92 & -23.31 & -0.44 \\
\hline
\end{tabular}

